\title{
Does Online Social Connectivity Promote Physical Activity in a Wearable Tracker-Based Intervention? A Pilot Randomized Controlled Study
}

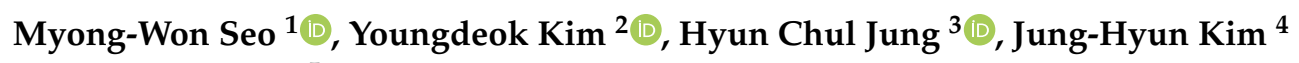 \\ and Jung-Min Lee ${ }^{5, *}$ \\ 1 Department of Taekwondo, College of Physical Education, Kyung Hee University, Global Campus, \\ Gyeonggi-do 17014, Korea; myongwonseo@khu.ac.kr \\ 2 Department of Kinesiology and Health Sciences, College of Humanities and Sciences, \\ Virginia Commonwealth University, Richmond, VA 23284, USA; kimy13@vcu.edu \\ 3 Department of Coaching, Kyung Hee University, Global Campus, Gyeonggi-do 17014, Korea; jhc@khu.ac.kr \\ 4 Department of Sports Medicine, Kyung Hee University, Global Campus, Gyeonggi-do 17014, Korea; \\ junghyun.kim@khu.ac.kr \\ 5 Department of Physical Education, Kyung Hee University, Global Campus, Gyeonggi-do 17014, Korea \\ * Correspondence: jungminlee@khu.ac.kr; Tel.: +82-3-1201-2736
}

Received: 7 September 2020; Accepted: 20 October 2020; Published: 23 October 2020

\begin{abstract}
Wearable activity trackers have gained popularity among individuals who want to track their physical activity (PA). The features of wearable tracking technology that are known to facilitate positive behavior changes such as self-monitoring and social connectedness) are well documented; yet, the existing evidence is not conclusive in the literature requiring further investigation. This study was an 8-week pilot randomized controlled study examining the effectiveness of PA intervention incorporating a wearable activity tracker's online connectivity feature. Forty participants were equally randomized into either an individual-based $(n=20)$ or a connected group $(n=20)$. A Jawbone UP24 tracker was provided to all participants in both groups as a means of self-monitoring PA for eight weeks, but the connected group was additionally instructed to share their PA levels with the others using the accompanying smartphone application. Participants' weekly step counts were evaluated each week to examine the change in PA. Participants' biometric variables such as body weight, body mass index, waist circumference, blood pressure, and psychological status, including self-efficacy (SE) and exercise motivation (EM), were measured from both groups before and after the intervention period. Additionally, the social support questionnaire (SSQ) was measured among the connected group. The statistical significance level was set at $<0.05$. The average step counts for eight weeks were significantly increased only in the connected group $(p<0.001)$. Significant differences in step count improved from the baseline to week 8 in the connected user group $(p<0.01)$, but only baseline vs. week 7 in the individual users. Also, no significant interaction effects for biometric variables, EM, and SE were founded. However, SSQ was significantly improved in the connected user group $(p<0.001)$. PA intervention combining a wearable activity tracker and online social connectivity feature shows a greater effectiveness of promoting PA than a wearable tracker alone
\end{abstract}

Keywords: accelerometer physical activity; average step count; social support; self-efficacy; exercise motivation

\section{Introduction}

Regular physical activity (PA) is associated with improved health, reduced chronic disease rates, and increases in overall quality of life [1]. However, most adults do not engage in the recommended 
level of PA and find that incorporating PA into the workday is often difficult [2,3]. An increased sedentary lifestyle has become a public health concern as one of the risk factors for various chronic diseases. This concern has brought about a tremendous volume of research and policy activity devoted to investigating and promoting PA [4]. Nonetheless, only about $25 \%$ of adults meet the 2008 Physical Activity Guidelines (150 min of moderate to vigorous PA per week) [5].

The wearable activity tracker market is overgrowing, and tracking daily PA is becoming popular among the general public [6-8]. Moreover, a growing number of companies and fitness facilities have adopted wearable activity trackers to promote employee wellness or to track clients' PA [9]. The trackers can as well provide web-based tailored PA advice through a website or smartphone application. As the advanced technology of wearable trackers has introduced, researchers have begun to apply wearable trackers into PA-related intervention studies, with results indicating that they are a promising technology for promoting healthy behaviors [10-12].

Several studies have demonstrated that PA self-monitoring increases an individual's awareness of his/her current PA level, which influences PA behavior of individuals in efforts towards their goal achievement. Franklin has emphasized the potential to increase PA by incorporating wearable technology in daily life [13]. Wang et al. studied the effect of wearing the Fitbit One and SMS text message on PA in overweight or obese adults [14]. They found that PA increased when the participants wore the activity tracker but did not change upon receiving SMS text messages. Cadmus-Bertram et al. assessed PA adherence by self-monitoring intervention with the Fitbit One tracker in overweight, obese, or postmenopausal women [15]. They reported that participants adhered well to wearing the activity tracker. Jakicic et al. studied the effects of intervention with wearable technology and found that participants in a weight-loss intervention group showed significant improvement compared to the control group [16]. However, there is still a lack of scientific research to systematically evaluate wearable activity trackers' when combined with the mobile integration feature, which connects users PA data and allows users to share their PA data with others via smartphone. This type of advanced technology may provide alternative ways of providing real-time support and motivation to individuals who try to increase or maintain their healthy PA behavior.

Social connection by sharing an individual's daily activity level with others (i.e., colleagues, friends, and family members) is one of the notable key features of wearable tracker technology [17]. Data are automatically summarized on the application by displaying an interactive and graphically attractive format via the website or connected mobile application. Such this feature has the potential to address the need for innovative methods of promoting healthy PA behavior. Therefore, we evaluated the effectiveness of monitoring and sharing PA on health behavior by (1) comparing individual users' PA and connected users' PA in terms of step measurements, (2) examining changes in PA while participants wore the wearable activity tracker over eight weeks. We hypothesized that wearing an activity tracker with the intervention of PA data sharing would bring positive behavioral changes toward PA.

\section{Materials and Methods}

\subsection{Participants}

A convenience sample of seventy-nine participants was recruited through word of mouth and posted fliers throughout the University. The participants were randomly assigned to either the individual or connected groups and provided with a Jawbone UP24 tracker worn on their non-dominant wrist for PA monitoring during all hours spent walking over 8 weeks, not including water activities (i.e., showering, swimming, or other activities involving submerging the tracker in water). To obtain valid PA data, participants who performed less than 1000 steps per day were excluded, and only those who had a minimum of $10 \mathrm{~h}$ per day with tracker wearing and four days of PA data per week were included for data analysis [18]. Therefore, forty participants' data (Individual group, $n=20$, male: 10, female: 10; Connected group, $n=20$, male: 12 , female: 8 ) were used in the present study. 
Participants completed both a physical activity readiness questionnaire (PAR-Q) and a general health history questionnaire to determine their participation eligibility. All participants were informed of potential risks and benefits of participation and signed an informed consent document approved by the Institutional Review Board.

\subsection{Anthropometric and Blood Pressure}

Anthropometric were performed twice (pre and post-test) to examine the differences before and after the study intervention. Participants' height was measured to the nearest $0.1 \mathrm{~cm}$ using a portable stadiometer (Seca 213, Hamburg, Germany), and body mass was measured to the nearest $0.01 \mathrm{~kg}$ wearing using a balance beam scale (Seca 813, Seca, Hamburg, Germany). Body mass index was calculated by dividing body weight $(\mathrm{kg})$ by height squared $\left(\mathrm{m}^{2}\right)$. Waist circumference was measured twice in the narrowest area of the trunk between the iliac crest and inferior rib using a tension-sensitive tape measure and averaged to the nearest $0.1 \mathrm{~cm}$. The percentage of body fat was assessed using a handheld bio-impedance analysis device (Omron HBF-306C, Omron Healthcare, Inc., Bannockburn, USA). Resting systolic and diastolic blood pressure (SBP, DBP; $\mathrm{mmHg}$ ) were measured twice using an upper arm blood pressure monitor (Omron BP785, Omron Healthcare, Inc., Bannockburn, USA).

\subsection{Intervention}

Prior to the intervention, all participants underwent seven days of free-living PA to obtain the baseline information using the SenseWear Mini armband (SenseWear Mini, Jawbone, San Francisco, CA, USA). The connected users were encouraged to interact with their partners, such as sending a feedback message based on their partners' daily PA through the 'TEAM' function. Also, Participants' step counts were recorded for seven days each week for eight weeks. The individual users were asked not to use the 'TEAM' function but to self-tracking his or her PA only (i.e., no sharing their PA data).

The connected users participated in the study with their friends, colleagues, and/or family members. For the connected users, researchers connected their devices using the 'TEAM' function on the application setting and instructed how to track their partners' daily PA patterns together with other optional functions (i.e., goal setting function and 3-day step duel challenge). After the connected users created their groups and added their partners (i.e., friends, colleagues, and family members) to their respective groups, they were able to monitor their data and their partner's PA data on the smartphone application. The PA information was manually extracted every seven days from the researchers' fitness tracker via the connected Jawbone application.

\subsection{Wearable Activity Tracker}

The SWA (SenseWear Mini Armband) is one of the most commonly used accelerometers for research purposes. The Jawbone UP24 is a wristband activity monitor $(66-81 \times 50-56 \mathrm{~mm}$ and 19-23 g) that can measure sleep, calories burned, steps, and food intake (by the manual update) throughout the day. This activity tracker operates by a three-dimensional accelerometer. It has a rechargeable battery with a 10-day lifespan and can be wirelessly synchronized with a mobile application (iOS or Android by Bluetooth technology. Step measurement by Jawbone UP24 tracker has undergone several validation studies, which found that the Jawbone UP24 tracker's steps were significantly equivalent to the criterion's measures $[19,20]$.

\subsection{Self-Efficacy, Exercise Motivation, and Social Support Questionnaire}

Surveys were performed twice to examine the differences between pre and post-test intervention periods. Perceived self-efficacy is defined as an individual's ability to perform specific behavior for the desired outcome [21]. To assess self-efficacy for PA, scales about emotional and environmental factors were used an 11-point scale, ranging from 0 to 10 ('not confident' to 'very confident') was used. A modified version of the behavioral regulation in exercise questionnaire-2 (BREQ-2) developed by Mullan et al. was used to assess exercise [22]. Several validation studies have reported that motivation 
and external influences have been identified and introjected. The BREQ-2 can assess intrinsic regulation. It has been utilized to develop the content better to understand exercise behavior [22,23]. Responses to a modified version of the BREQ-2 were scored on a 7-point scale, ranging from 1 to 7 ('not at all true' to 'very true').

The Social Support for Exercise Scale developed by Sallis et al. was used to evaluate sharing PA data as social support [24]. Participants answered that they often experienced social support for PA with a 5-point scale, ranging from 1 to 5 ('none' to 'very often').

The word 'Exercise' was replaced with 'Physical Activity' on the questionnaire. The reliability and validity of the social support questionnaire have been studied by Liang et al. report that a Chronba's alpha $>0.70$ for reliability and significant association with objectively measured PA $(r=0.21-0.35$. $p<0.05)$ for validity [25].

\subsection{Data Analysis}

All statistical analyses were performed with SPSS 25.0 (SPSS Inc., Chicago, IL, USA) with an alpha level of 0.05 . All data were expressed as mean, standard deviations, $95 \%$ confidence intervals, and effects size. Repeated measures ANOVA was used to assess group, time, and group by time interaction effects. If any significant interaction effects were found, the dependent $T$-test for the post-hoc test was used to compare the baseline data between each week, respectively. In addition to dependent $t$-tests and effect size was indexed to examine the effect of the difference between the baseline and intervention period. Effect sizes were calculated as partial eta-squared $\left(\eta^{2}\right.$; small $\geq 0.01$, medium $\geq 0.06$, large $\geq 0.14$ ) values with repeated measures ANOVA and Cohens' $d$ (small $\geq 0.2$, medium $\geq 0.5$, large $\geq 0.8$ ) was used to assess the standardized difference between the baseline and post-tests in each group.

\section{Results}

The average steps and standard deviations for each group are presented in Figure 1. Baseline step counts for the individual user group and connected user group were $6805.16 \pm 3061.43$ and $6516.11 \pm 2465.88 \mathrm{steps} /$ day, respectively. A similar step pattern (average step $=6808.32 \pm 2628.79$ ) was observed in the individual user, and an increased step pattern (average step $=9564.10 \pm 2990.83$ ) was shown in the connected user group over eight weeks. Participants' anthropometric characteristics and psychological factors are presented in Table 1. Social support score increased significantly in the connected user group, whereas no significant change was observed in the individual user group during the intervention period. Also, there were no significant interactions on weight, body mass index, waist circumference, body fat, SBP, DBP, exercise motivation, and self-efficient during the intervention.

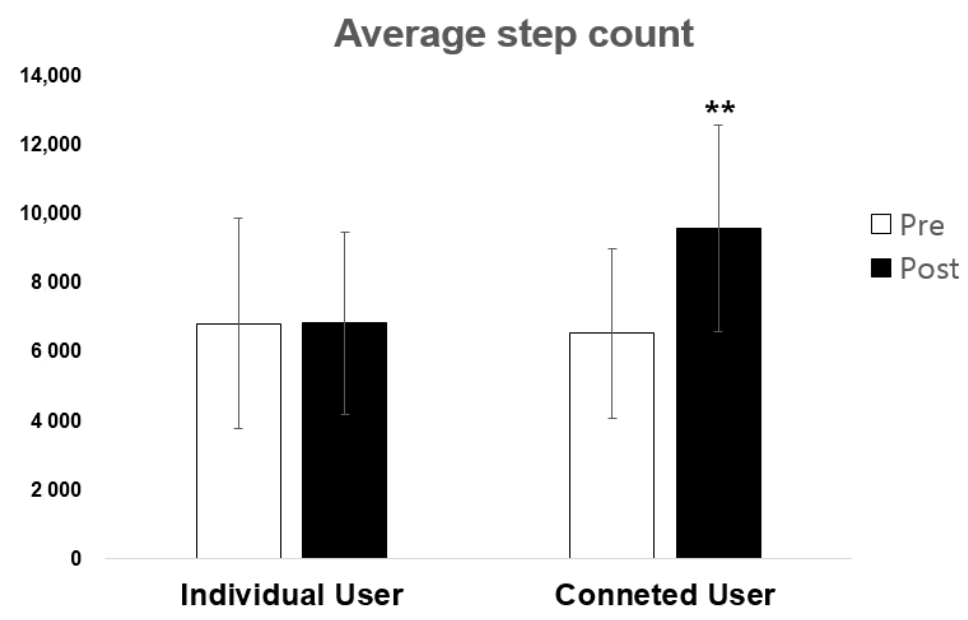

Figure 1. Change in average step count in individual and connected groups between baseline and intervention period. ${ }^{* *} p<0.01$. 
Table 1. Mean $(95 \% \mathrm{CI})$ changes in biometric measurement pre- and post-test (Mean $\pm \mathrm{SD})$.

\begin{tabular}{|c|c|c|c|c|c|c|c|c|}
\hline & \multicolumn{3}{|c|}{ Individual $(n=20)$} & \multicolumn{3}{|c|}{ Connected Group $(n=20)$} & \multirow[t]{2}{*}{$\mathrm{G} \times \mathrm{T}$} & \multirow[t]{2}{*}{$\eta_{p}^{2}$} \\
\hline & Baseline & Post & ES & Baseline & Post & ES & & \\
\hline $\begin{array}{l}\text { Weight } \\
\text { (kg) }\end{array}$ & $\begin{array}{l}72.55 \pm 15.09 \\
(65.7 \text { to } 79.44)\end{array}$ & $\begin{array}{c}72.97 \pm 15.39 \\
(66.09 \text { to } 79.84)\end{array}$ & 0.18 & $\begin{array}{c}68.68 \pm 15.32 \\
(61.79 \text { to } 75.56)\end{array}$ & $\begin{array}{c}68.87 \pm 14.97 \\
(62.00 \text { to } 75.75)\end{array}$ & 0.11 & 0.17 & 0.01 \\
\hline $\begin{array}{c}\mathrm{BMI} \\
\left(\mathrm{kg} \cdot \mathrm{m}^{-2}\right)\end{array}$ & $\begin{array}{c}23.58 \pm 3.62 \\
(22.01 \text { to } 25.15)\end{array}$ & $\begin{array}{c}23.70 \pm 3.63 \\
(22.14 \text { to } 25.25)\end{array}$ & 0.17 & $\begin{array}{c}24.52 \pm 3.31 \\
(22.95 \text { to } 26.09)\end{array}$ & $\begin{array}{c}24.61 \pm 3.24 \\
(23.05 \text { to } 26.17)\end{array}$ & 0.82 & 0.02 & 0.00 \\
\hline $\mathrm{WC}(\mathrm{cm})$ & $\begin{array}{c}80.52 \pm 8.17 \\
(76.23 \text { to } 84.81)\end{array}$ & $\begin{array}{c}79.23 \pm 7.79 \\
(75.14 \text { to } 83.34)\end{array}$ & 0.14 & $\begin{array}{c}79.55 \pm 10.63 \\
(75.26 \text { to } 83.84)\end{array}$ & $\begin{array}{c}79.95 \pm 10.17 \\
(75.85 \text { to } 84.05)\end{array}$ & 0.14 & 2.96 & 0.07 \\
\hline $\begin{array}{c}\text { Body fat } \\
(\%)\end{array}$ & $\begin{array}{c}18.97 \pm 8.28 \\
(15.69 \text { to } 22.24)\end{array}$ & $\begin{array}{c}19.58 \pm 8.19 \\
(16.27 \text { to } 22.88)\end{array}$ & 0.03 & $\begin{array}{c}23.54 \pm 6.03 \\
(20.26 \text { to } 26.82)\end{array}$ & $\begin{array}{c}23.08 \pm 6.29 \\
(19.77 \text { to } 26.38)\end{array}$ & 0.25 & 2.7 & 0.01 \\
\hline $\begin{array}{c}\text { SBP } \\
(\mathrm{mmHg})\end{array}$ & $\begin{array}{c}117.60 \pm 11.82 \\
(111.72 \text { to } \\
123.48)\end{array}$ & $\begin{array}{c}106.25 \pm 21.78 \\
(97.65 \text { to } \\
114.85)\end{array}$ & 0.33 & $\begin{array}{c}115.8 \pm 14.07 \\
(109.92 \text { to } \\
121.68)\end{array}$ & $\begin{array}{c}115.05 \pm 15.75 \\
(106.45 \text { to } 123.65)\end{array}$ & 0.07 & 3.57 & 0.09 \\
\hline $\begin{array}{c}\text { DBP } \\
(\mathrm{mmHg})\end{array}$ & $\begin{array}{c}75.25 \pm 6.47 \\
(70.80 \text { to } 77.70) \\
\end{array}$ & $\begin{array}{c}70.10 \pm 5.74 \\
(66.66 \text { to } 73.55) \\
\end{array}$ & 0.58 & $\begin{array}{c}80.0 \pm 8.62 \\
(76.55 \text { to } 83.45) \\
\end{array}$ & $\begin{array}{c}76.55 \pm 9.10 \\
(73.11 \text { to } 80.00)\end{array}$ & 0.52 & 0.11 & 0.00 \\
\hline EM & $\begin{array}{c}68.21 \pm 10.57 \\
(63.06 \text { to } 73.37)\end{array}$ & $\begin{array}{c}69.00 \pm 8.98 \\
(64.53 \text { to } 73.47)\end{array}$ & 0.11 & $\begin{array}{c}70.21 \pm 11.61 \\
(64.21 \text { to } 76.22)\end{array}$ & $\begin{array}{c}72.29 \pm 10.32 \\
(67.07 \text { to } 77.50)\end{array}$ & 0.17 & 0.17 & 0.01 \\
\hline Self-efficient & $\begin{array}{c}70.35 \pm 25.79 \\
(57.99 \text { to } 82.71)\end{array}$ & $\begin{array}{c}68.80 \pm 20.13 \\
(68.27 \text { to } 93.63)\end{array}$ & 0.06 & $\begin{array}{c}72.57 \pm 22.54 \\
\text { (59.11 to } 78.49)\end{array}$ & $\begin{array}{c}70.14 \pm 22.86 \\
\text { (58.56 to } 81.73)\end{array}$ & 0.22 & 0.01 & 0.00 \\
\hline $\begin{array}{l}\text { Social } \\
\text { support }\end{array}$ & & & & $\begin{array}{c}26.17 \pm 9.78 \\
(21.30 \text { to } 31.03)\end{array}$ & $\begin{array}{l}29.72 \pm 10.80^{* * * *} \\
(24.35 \text { to } 35.09)\end{array}$ & 0.46 & & \\
\hline
\end{tabular}

Note. N/A: Individual users did not get any other social support, BMI: body mass index, WC: waist circumference, SBP: systolic blood pressure, DBP: diastolic blood pressure, EM: exercise motivation, ES: Cohen's $d, \mathrm{G} \times \mathrm{T}$ : Interaction, *** $p<0.001$.

Repeated measures ANOVA revealed that only significant interaction effects were found in average number of steps per week $\left(F=47.74, p<0.001, \eta^{2}{ }_{p}=0.557\right)$. The number of step counts improved significantly in the connected user group ( $p<0.001$, Cohen's $d$ : 0.98$)$, whereas no significant change was found in the individual user group. The participants in the connected user group have a greater increase at the mid-intervention time point, Week $1(p<0.001$, Cohen's $d: 1.53)$, and the average effect size over eight weeks are 1.53 (Table 2). The effect size for step measures between the individual user group and the connected user group ranged from 0.14 to 0.98 (Cohen's $d$, Baseline: 0.14, week 1: 0.75, week 2: 0.90, week 3: 0.82, week 4: 1.10 , week 5: 0.98, week 6: 0.69, week 7: 0.58, week 8: $0.65)$. The largest effect between the two groups was observed in week four, and the only medium-size effect was found at week 7 (7710.34 \pm 2780.29 steps/day, Cohen's $d$ : 0.75$)$ compared to the baseline $(6805.16 \pm 3061.43$ steps/day) in individual users.

Table 2. Changes in step count per week in individual and connected users (Mean \pm SD).

\begin{tabular}{cccccc}
\hline & \multicolumn{2}{c}{ Individual Users } & \multicolumn{2}{c}{ Connected Users } & \multirow{2}{*}{ Independent ES } \\
\cline { 1 - 4 } & Step Count & Dependent ES & Step Count & Dependent ES & \\
\hline Baseline & $6805.16 \pm 3061.43$ & & $6516.11 \pm 2465.88$ & & 0.14 \\
Vs. Week 1 & $7021.91 \pm 3447.47$ & 0.15 & $9565.03 \pm 3379.29$ & $1.53^{* * *}$ & 0.75 \\
Vs. Week 2 & $6685.69 \pm 2879.95$ & 0.08 & $9749.37 \pm 3914.10$ & $1.47^{* * *}$ & 0.90 \\
Vs. Week 3 & $6927.22 \pm 3302.31$ & 0.07 & $9694.43 \pm 3384.53$ & $1.52^{* * *}$ & 0.82 \\
Vs. Week 4 & $6430.2 \pm 2650.97$ & 0.20 & $9717.04 \pm 3334.59$ & $1.19^{* * *}$ & 1.10 \\
Vs. Week 5 & $6060.75 \pm 2493.23$ & 0.39 & $8649.07 \pm 2762.55$ & $1.40^{* * *}$ & 0.98 \\
Vs. Week 6 & $6706.56 \pm 3498.66$ & 0.03 & $9007.20 \pm 32214.88$ & $1.44^{* *}$ & 0.69 \\
Vs. Week 7 & $7710.34 \pm 2780.29$ & $0.76^{*}$ & $10476.00 \pm 4743.73$ & $1.10^{* *}$ & 0.58 \\
Vs. Week 8 & $6747.19 \pm 2806.32$ & 0.09 & $9275.14 \pm 3147.57$ & $1.24^{* * *}$ & 0.65 \\
\hline
\end{tabular}

Note. ES: Cohens ${ }^{\prime}{ }^{*} p<0.05,{ }^{* *} p<0.01,{ }^{* * *} p<0.01$.

\section{Discussion}

Tremendous efforts have been made to identify creative strategies to promote and sustain PA for the sake of better public health. Numerous studies regarding the effect of the text-message intervention on health behavior have been conducted to examine the effectiveness of social support 
on health promotion and indicated improved PA with text-messaging [14,26-30]. The effects of self-monitoring on PA promotion have also been studied and indicate a significant increase in PA with self-monitoring $[15,16,31-34]$. Also, the combination of online partner communication and wearable PA tracking technology has shown promise in positive PA behavior. Because of the outcomes of previous works by others, therefore, we hypothesized that wearing an activity tracker with the intervention of sharing PA data with partners would bring the positive behavioral changes that would consequently provide benefits on anthropometric variables such as BW, WC, and BMI.

In the present study, we found that connected users increased the number of average steps taken, where no significant change was observed in individual users. Since a more significant change in step count was observed in connected users than individual users (baseline vs. week 7), it seems that sharing PA data can positively affect PA by motivating the users to engage in improved health behavior. Although previous studies have reported that social support carries a positive impact on improving PA and useful for PA promotion, controversial results may limit confirming the effectiveness of social support. Kouvonen et al. reported that participating in leisure-time physical activities is positively related to social support from the closest person to an individual [35]. Morrissey et al. studied the relationship between social support and adolescent engagement in moderate to vigorous PA (MVPA) across a five-year follow-up. They reported that MVPA increased with family and friend support, showing a moderate relationship between MVPA and social support $(r=0.32$ to 0.58$)$ [36]. However, a systematic review and meta-analysis demonstrated the relationship between social support and physical activity behavior; they found that social support did not significantly affect PA [37]. In the present study, the social support score in the connected users was increased from 26.17 to 29.72. It might be small changes in magnitude in effect size, but ways in which friends and colleagues provide social support can likely influence PA levels.

Although PA was increased by the intervention periods, self-efficacy was not improved in the connected user group. Increased self-efficacy, a person's belief in performing a specific action to achieve a goal within reach of his or her capabilities, was not reflected in the results of the present study [21]. Studies that are longer in duration and include larger, more diverse populations than the present 8-week intervention will be needed to ascertain the relationship between increased PA and self-efficacy. The scores for exercise motivation are not changed in both individual and connected user groups, consistent with Booth et al. [38].

The previous study participants expressed that performing PA with family members and friends was a key and social reinforcement strongly associated with their exercise-related behavior. While the connected group users engaged in more PA compared to the individual users, weight, BMI, waist circumference, body fat, and blood pressure were not significantly improved. It is speculated that wearable trackers' motivations and applications may differ between individual and connected users. As the connected users were allowed to share their PA with their partners, they might focus exclusively on increasing their PA while monitoring partners' PA. The connected users might have relaxed if they had more steps than their teammates. However, since the individual users were not allowed to use the 'TEAM' function, they focused on their overall self-monitoring steps. Consequently, the individual users might utilize other functions of the application (i.e., goal setting, diet control, and sleep duration), being self-aware rather than monitoring others' PA, affecting weight, blood pressure, and waist circumference. Our results on individual users are inconsistent with those of Jakicic et al., who examined the change in participants' weight by the technology-enhanced weight loss intervention [16]. They reported significant improvement in weight, fitness, body composition, and PA. Therefore, the effects of sharing PA data on anthropometrics such as weight or waist circumference monitoring would be the next target for PA intervention research using wearable devices

The limitations of this study are that participants' compliance with wearing the Jawbone UP tracker was not monitored throughout the intervention. There was no reimbursement for participating in the study and no means to enforce compliance in wearing the tracker. For a generalization of the result, the present study population was limited to college students with their friends, colleagues, 
and family members. Although it has been reported that the effect of social support on adolescents' PA is significant, adolescents or children were not recruited for this study [36]. Participants' diet might affect their energy expenditure and weight, but those variables were neither controlled nor monitored in the present study. This study also covered a relatively short period (8 weeks) to permit a thorough explanation of the effects of the intervention. Therefore, further studies with long-term intervention and diverse populations and controlling diet and user compliance are needed to demonstrate the effect of sharing PA on health behavior.

\section{Conclusions}

In the present study, the connected users showed better performance on increasing PA and social support. However, the scores of self-efficacy, exercise motivation were not significantly changed. Biometric variables such as body weight, body mass index, waist circumference, blood pressure were not significantly changed in both individual and connected users across time. Our finding suggests that the wearable activity tracker utilizing an online connection with other users shows the effectiveness of promoting PA and might be an alternative method to promote healthy PA behavior.

Author Contributions: Data curation J.-M.L.; Formal analysis M.-W.S., Y.K. and J.-M.L.; Investigation M.-W.S., H.C.J. and J.-M.L.; Methodology Y.K., J.-H.K. and J.-M.L.; Project administration J.-M.L.; Writing-Original draft, M.-W.S.; Writing-Review \& editing, Y.K., H.C.J., J.-H.K. and J.-M.L. All authors have read and agreed to the published version of the manuscript.

Funding: This work was supported by a grant from Kyung Hee University in 2018 (KHU-20181168).

Acknowledgments: The authors would like to thank all participants who participated in this study.

Conflicts of Interest: The authors have no conflict of interest to declare.

\section{References}

1. Lee, J.M.; Kim, Y.; Welk, G.J. Validity of consumer-based physical activity monitors. Med. Sci. Sports Exerc. 2014, 46, 1840-1848. [CrossRef]

2. Friedenreich, C.M.; Orenstein, M.R. Physical activity and cancer prevention: Etiologic evidence and biological mechanisms. J. Nutr. 2002, 132, 3456S-3464S. [CrossRef]

3. Blackwell, D.L.; Clarke, T.C. State Variation in Meeting the 2008 Federal Guidelines for Both Aerobic and Muscle-strengthening Activities Through Leisure-time Physical Activity Among Adults Aged 18-64: United States, 2010-2015. Natl. Health Stat. Rep. 2018, 112, 1-22.

4. Schmid, D.; Ricci, C.; Baumeister, S.E.; Leitzmann, M.F. Replacing Sedentary Time with Physical Activity in Relation to Mortality. Med. Sci. Sports Exerc. 2016, 48, 1312-1319. [CrossRef] [PubMed]

5. Leider, J.; Chriqui, J.F.; Thrun, E. Associations between active living-oriented zoning and no adult leisure-time physical activity in the US. Prev. Med. 2016, 95, S120-S125. [CrossRef] [PubMed]

6. Chen, S.; Zhu, X.; Welk, G.J.; Kim, Y.; Lee, J.; Meier, N.F. Using Sensewear armband and diet journal to promote adolescents' energy balance knowledge and motivation. J. Sport Health Sci. 2014, 3, 326-332. [CrossRef]

7. Brickwood, K.-J.; Watson, G.; O’Brien, J.; Williams, A.D. Consumer-Based Wearable Activity Trackers Increase Physical Activity Participation: Systematic Review and Meta-Analysis. JMIR mHealth uHealth 2019, 7, e11819. [CrossRef]

8. Böhm, B.; Karwiese, S.D.; Böhm, H.; Oberhoffer, R. Effects of Mobile Health Including Wearable Activity Trackers to Increase Physical Activity Outcomes Among Healthy Children and Adolescents: Systematic Review. JMIR mHealth uHealth 2019, 7, e8298. [CrossRef]

9. Bravata, D.M.; Smith-Spangler, C.; Sundaram, V.; Gienger, A.L.; Lin, N.; Lewis, R.; Stave, C.D.; Olkin, I.; Sirard, J.R. Using pedometers to increase physical activity and improve health: A systematic review. J. Am. Med. Assoc. 2007, 298, 2296-2304. [CrossRef]

10. Ridgers, N.D.; Timperio, A.; Brown, H.; Ball, K.; Macfarlane, S.; Lai, S.K.; Richards, K.; Mackintosh, K.A.; McNarry, M.A.; Foster, M. Wearable activity tracker use among Australian adolescents: Usability and acceptability study. JMIR mHealth uHealth 2018, 6, e86. [CrossRef] 
11. Lynch, B.M.; Nguyen, N.H.; Moore, M.M.; Reeves, M.M.; Rosenberg, D.; Boyle, T.; Vallance, J.K.; Milton, S.; Friedenreich, C.M.; English, D.R. A randomized controlled trial of a wearable technology-based intervention for increasing moderate to vigorous physical activity and reducing sedentary behavior in breast cancer survivors: The ACTIVATE Trial. Cancer 2019, 125, 2846-2855. [PubMed]

12. Kononova, A.; Li, L.; Kamp, K.; Bowen, M.; Rikard, R.; Cotten, S.; Peng, W. The Use of Wearable Activity Trackers Among Older Adults: Focus Group Study of Tracker Perceptions, Motivators, and Barriers in the Maintenance Stage of Behavior Change. JMIR mHealth uHealth 2019, 7, e9832. [CrossRef] [PubMed]

13. Franklin, N.C. Technology to promote and increase physical activity in heart failure. Heart Fail. Clin. 2015, 11, 173-182. [CrossRef] [PubMed]

14. Wang, J.B.; Cadmus-Bertram, L.A.; Natarajan, L.; White, M.M.; Madanat, H.; Nichols, J.F.; Ayala, G.X.; Pierce, J.P. Wearable sensor/device (Fitbit One) and SMS text-messaging prompts to increase physical activity in overweight and obese adults: A randomized controlled trial. Telemed. e-Health 2015, 21, 782-792. [CrossRef]

15. Cadmus-Bertram, L.; Marcus, B.H.; Patterson, R.E.; Parker, B.A.; Morey, B.L. Use of the Fitbit to Measure Adherence to a Physical Activity Intervention Among Overweight or Obese, Postmenopausal Women: Self-Monitoring Trajectory During 16 Weeks. JMIR mHealth uHealth 2015, 3, e96. [CrossRef]

16. Jakicic, J.M.; Davis, K.K.; Rogers, R.J.; King, W.C.; Marcus, M.D.; Helsel, D.; Rickman, A.D.; Wahed, A.S.; Belle, S.H. Effect of wearable technology combined with a lifestyle intervention on long-term weight loss: The IDEA randomized clinical trial. J. Am. Med. Assoc. 2016, 316, 1161-1171. [CrossRef]

17. Culhane, K.M.; O'Connor, M.; Lyons, D.; Lyons, G.M. Accelerometers in rehabilitation medicine for older adults. Age Ageing 2005, 34, 556-560. [CrossRef]

18. Kang, M.; Bassett, D.R.; Barreira, T.V.; Tudor-Locke, C.; Ainsworth, B.; Reis, J.P.; Strath, S.; Swartz, A. How many days are enough? A study of 365 days of pedometer monitoring. Res. Q. Exerc. Sport 2009, 80, 445-453. [CrossRef]

19. An, H.-S.; Jones, G.C.; Kang, S.-K.; Welk, G.J.; Lee, J.-M. How valid are wearable physical activity trackers for measuring steps? Eur. J. Sport Sci. 2016, 17, 360-368. [CrossRef]

20. Kooiman, T.J.; Dontje, M.L.; Sprenger, S.R.; Krijnen, W.P.; van der Schans, C.P.; de Groot, M. Reliability and validity of ten consumer activity trackers. BMC Sports Sci. Med. Rehabil. 2015, 7, 1-11. [CrossRef]

21. Luszczynska, A.; Scholz, U.; Schwarzer, R. The general self-efficacy scale: Multicultural validation studies. J. Psychol. 2005, 139, 439-457. [CrossRef] [PubMed]

22. Mullan, E.; Markland, D. Variations in self-determination across the stages of change for exercise in adults. Motiv. Emot. 1997, 21, 349-362. [CrossRef]

23. Markland, D.; Tobin, V. A modification to the behavioural regulation in exercise questionnaire to include an assessment of amotivation. J. Sport Exerc. Psychol. 2004, 26, 191-196. [CrossRef]

24. Sallis, J.F.; Grossman, R.M.; Pinski, R.B.; Patterson, T.L.; Nader, P.R. The development of scales to measure social support for diet and exercise behaviors. Prev. Med. 1987, 16, 825-836. [CrossRef]

25. Liang, Y.; Lau, P.W.; Huang, W.Y.; Maddison, R.; Baranowski, T. Validity and reliability of questionnaires measuring physical activity self-efficacy, enjoyment, social support among Hong Kong Chinese children. Prev. Med. Rep. 2014, 1, 48-52. [CrossRef] [PubMed]

26. Fjeldsoe, B.S.; Miller, Y.D.; Marshall, A.L. MobileMums: A randomized controlled trial of an SMS-based physical activity intervention. Ann. Behav. Med. 2010, 39, 101-111. [CrossRef] [PubMed]

27. Gerber, B.S.; Stolley, M.R.; Thompson, A.L.; Sharp, L.K.; Fitzgibbon, M.L. Mobile phone text messaging to promote healthy behaviors and weight loss maintenance: A feasibility study. Health Inform. J. 2009, 15, 17-25. [CrossRef]

28. Napolitano, M.A.; Hayes, S.; Bennett, G.G.; Ives, A.K.; Foster, G.D. Using Facebook and Text Messaging to Deliver a Weight Loss Program to College Students. Obesity 2013, 21, 25-31. [CrossRef]

29. Patrick, K.; Raab, F.; Adams, M.A.; Dillon, L.; Zabinski, M.; Rock, C.L.; Griswold, W.G.; Norman, G.J. A text message-based intervention for weight loss: Randomized controlled trial. J. Med. Internet Res. 2009, 11, e1. [CrossRef]

30. Shapiro, J.R.; Bauer, S.; Hamer, R.M.; Kordy, H.; Ward, D.; Bulik, C.M. Use of Text Messaging for Monitoring Sugar-sweetened Beverages, Physical Activity, and Screen Time in Children: A Pilot Study. J. Nutr. Educ. Behav. 2008, 40, 385-391. [CrossRef] 
31. Aittasalo, M.; Miilunpalo, S.; Kukkonen-Harjula, K.; Pasanen, M. A randomized intervention of physical activity promotion and patient self-monitoring in primary health care. Prev. Med. 2006, 42, 40-46. [CrossRef] [PubMed]

32. Duncan, M.J.; Vandelanotte, C.; Trost, S.G.; Rebar, A.L.; Rogers, N.; Burton, N.W.; Murawski, B.; Rayward, A.; Fenton, S.; Brown, W.J. Balanced: A randomised trial examining the efficacy of two self-monitoring methods for an app-based multi-behaviour intervention to improve physical activity, sitting and sleep in adults. BMC Public Health 2016, 16, 1-14. [CrossRef] [PubMed]

33. Conroy, M.B.; Yang, K.; Elci, O.U.; Gabriel, K.P.; Styn, M.A.; Wang, J.; Kriska, A.M.; Sereika, S.M.; Burke, L.E. Physical activity self-monitoring and weight loss: 6-month results of the SMART trial. Med. Sci. Sports Exerc. 2011, 43, 1568-1574. [CrossRef] [PubMed]

34. Turner-McGrievy, G.M.; Beets, M.W.; Moore, J.B.; Kaczynski, A.T.; Barr-Anderson, D.J.; Tate, D.F. Comparison of traditional versus mobile app self-monitoring of physical activity and dietary intake among overweight adults participating in an mHealth weight loss program. J. Am. Med. Inform. Assoc. 2013, 20, 513-518. [CrossRef]

35. Kouvonen, A.; De Vogli, R.; Stafford, M.; Shipley, M.J.; Marmot, M.G.; Cox, T.; Vahtera, J.; Väänänen, A.; Heponiemi, T.; Singh-Manoux, A.; et al. Social support and the likelihood of maintaining and improving levels of physical activity: The Whitehall II Study. Eur. J. Public Health 2011, 22, 514-518. [CrossRef]

36. Morrissey, J.L.; Janz, K.F.; Letuchy, E.M.; Francis, S.L.; Levy, S.M. The effect of family and friend support on physical activity through adolescence: A longitudinal study. Int. J. Behav. Nutr. Phys. Act. 2015, 12, 103. [CrossRef]

37. Laird, Y.; Fawkner, S.; Kelly, P.; McNamee, L.; Niven, A. The role of social support on physical activity behaviour in adolescent girls: A systematic review and meta-analysis. Int. J. Behav. Nutr. Phys. Act. 2016, 13, 1-14. [CrossRef]

38. Booth, M.L.; Owen, N.; Bauman, A.; Clavisi, O.; Leslie, E. Social-cognitive and perceived environment influences associated with physical activity in older Australians. Prev. Med. 2000, 31, 15-22. [CrossRef]

Publisher's Note: MDPI stays neutral with regard to jurisdictional claims in published maps and institutional affiliations.

(C) 2020 by the authors. Licensee MDPI, Basel, Switzerland. This article is an open access article distributed under the terms and conditions of the Creative Commons Attribution (CC BY) license (http://creativecommons.org/licenses/by/4.0/). 